\title{
BACTERIORRODOPSINA: UNA MOLÉCULA PECULIAR
}

\author{
MIGUEL A. REYES-MARTINEZ' Y AMPARO I. ZAVALETA'
}

\begin{abstract}
RESUMEN
La bacteriorrodopsina (bR) es una proteína que, al ser estimulada por la luz, funciona como una bomba de protones interviniendo en la síntesis de ATP mediante un proceso de fotofosforilación que convierte la energía lumínica en química (fotosíntesis). La bR codificada por el gen bop, es el constituyente de la membrana celular de las haloarqueas extremas, llega a ocupar hasta el $50 \%$ de ésta cuando hay concentraciones bajas de $\mathrm{O}_{2}$, demostrando la gran adaptación de estos microorganismos a condiciones anaeróbicas. Desde que fue propuesta la función fotorreceptora de la bR, numerosos estudios se han realizado con el fin de elucidar su secuencia aminoacídica, su conformación estructural, sus propiedades fisicoquímicas, las características de su expresión y regulación génica. Las excelentes propiedades fotoquímicas y termodinámicas de la bR la hacen una molécula peculiar y candida ta para aplicaciones biotecnológicas en biocomputación como memorias ópticas, sistemas fotoeléctricos y en biomateriales, siendo de gran interés comercial las fuentes de aislamiento y producción. En esta revisión, se describe la génesis, función, expresión génica y aplicación biotecnológica de la bacteriorrodopsina.
\end{abstract}

Palabras clave: Bacteriorrodopsina, arqueas halófilas extremas, bomba de protones, gen bop.

\section{SUMMARY}

The bacteriorhodopsin $(\mathrm{bR})$ is a protein which plays a role as a proton pump when is stimulated by light. The bR is involved in ATP's synthesis through a process of transduction, turning light energy into chemical energy (photosynthesis). The bR codified by bop gene and located in the cell envelope, covers up to $50 \%$ of the extreme haloarchaeas when the environment is anaerobic. This feature shows a maximum degree of adjustment to anaerobic conditions of halophilic microorganism. Since the bR function as photoreceptor was proposed, several studies have been done in order to elucidate its amino acid sequence, structural conformation, physicochemical properties and expression and gene regulation characteristics. The excellent $b R^{\prime} s$ photochemical and thermodynamic properties make it a peculiar molecule and a candidate to biotechnological applications in biocomputation for example in optical memories, in photoelectric systems and in biomaterials. For that reason, bR's sources of isolation and production have received a great commercial interest. In this review, the bR genesis, main function, gene expression and biotechnological application of the bacteriorhodopsin is described.

Key words: Bacteriorhodopsin, extremely halophilic archaea, proton pump, bop gene.

\section{INTRODUCCIÓN}

Los ambientes extremos como fuentes termales "gaysers", chimeneas volcánicas, solfataras (fuentes naturales de azufre hirviente), glaciares, aguas submarinas de elevadas presiones, fuentes geotérmicas de hierro candente, lagos y suelos hipersalinos son ambientes estresantes donde crecen microorganismos adaptados a condiciones extremas de temperatura, $\mathrm{pH}$, salinidad y bajas

\footnotetext{
- Laboratorio de Biologia Molecular. Instituto de Quimica Biológica, Microbiología y Biotecnología. Facultad de Farmacia y Bioquímica. Universidad Nacional Mayor de San Marcos
}

concentraciones de oxígeno. Estos microorganismos son denominados extremófilos y poseen además gran diversidad metabólica que incluye fotótrofos oxigénicos y anoxigénicos, heterótrofos aerobios, fermentadores, denitrificadores, sulfatos reductores y metanógenos. Las haloarqueas son un grupo de extremófilos, denominados halófilos por su peculiar adaptación a medios hipersalinos, son muy estudiados y han recibido gran atención en los últimos años debido al gran potencial biotecnológico de sus metabolitos secundarios, enzimas y moléculas fascinantes como la bacteriorrodopsina (bR) $(1,2)$.

En 1977 los organismos vivientes fueron clasificados en tres grandes dominios: Eucaria, Eubacteria 
y Archaea, esta clasificación está basada en el análisis de las secuencias de los genes ribosómicos $16 \mathrm{~S}$ y de otras moléculas indispensables para la supervivencia consideradas cronómetros evolutivos, siendo Carl Woese el pionero en estos estudios (1, 2). Los microorganismos del dominio Archaea predominan en los ambientes extremos, así las haloarqueas dominan los ambientes hipersalinos naturales o de origen antropogénico $(1,2,3)$.

El dominio Archaea se divide en tres reinos: Euriarqueota, Crenarqueota y Koriarqueota. Las haloarqueas pertenecen al reino Euriarqueota y a la familia Halobacteriaceae. En la actualidad, existen 18 géneros reconocidos: Haloarcula, Halobacterium, Halobaculum, Halobiforma, Halococcus, Haloferax, Halogeometricum, Halomicrobium, Halorhabdus, Halorubrum, Halosimplex, Haloterrigena, Natrialba, Natrinema, Natronobacterium, Natronococcus, Natronomonas y Natronorubrum, la mayoría son aerobios estrictos o anaerobios facultativos (3).

Las haloarqueas son microorganismos que crecen óptimamente entre 3,4 - 5,1 M (20-30\%) de $\mathrm{NaCl}$. Estos acumulan $\mathrm{KCl}$ en concentraciones molares como un mecanismo osmoadaptativo para contrarrestar la elevada salinidad del medio y evitar la plasmolisis $(4,5)$. Frente a estas condiciones estresantes las haloarqueas han adaptado también su proteosoma para mantener una correcta conformación estructural, evitando la desnaturalización, agregación y precipitación de las proteínas. Generalmente los aminoácidos de las proteínas de membrana son de naturaleza electronegativa facilitando una correcta solvatación con su medio explicándose así la estabilidad de membrana en medios hipersalinos (6).

Halobacterium salinarum es una de las haloarqueas más representativas y mejor estudiadas, es quimioorganotrofo y fotótrofo facultativo, presenta una maquinaria metabólica que le permite producir ATP mediante fosforilación oxidativa y fosforilación a nivel de sustrato. Considerando el paradigma de la estructura mitocondrial podría esperarse una agrupación de proteínas (complejos proteicos) parecida a la cadena transportadora de electrones conectadas por transportadores móviles (ubiquinonas) en la membrana celular, pero en contraposición, los complejos proteicos de $H$. salinarum pueden estar fusionados formando supercomplejos y presentar composiciones inusuales como una forma de adaptación al medio hipersalino, además muestra diferencias metabólicas como por ejemplo cuando la arginina es convertida a glutamato vía arginina desaminasa y luego entra al ciclo del ácido cítrico $(7,8,9)$.

Algunas haloarqueas han desarrollado un mecanismo fotosintético que les permite enfrentar las bajas concentraciones de oxígeno que son capaces de retener estos ambientes hipersalinos, que tiene por consecuencia la drástica disminución de la fosforilación oxidativa y producción de ATP, por lo tanto este mecanismo fotosintético evita la muerte celular por falta de energía (10). Este mecanismo fotosintético produce ATP de una forma similar al realizado en la cadena transportadora, pero a diferencia de ésta los protones expulsados no provienen de los complejos proteicos sino de una bomba de protones fotoexitable. En este mecanismo adaptativo participa la bacteriorrodopsina (bR), una de las primeras proteínas estudiadas por métodos de alta especificidad y sensibilidad como: Infrarrojo, Raman y Espectroscopia de Resonancia Magnética Nuclear (RMN) en estado sólido. En base a los estudios de la bR se han diseñado y elaborado instrumentos sofisticados para detectar cambios conformacionales de las proteínas en tiempo real a longitudes de onda visible con resoluciones que alcanzan los femtosegundos (billonésima parte de un milisegundo). La bR ha recibido la denominación de «Molécula Modelo» debido a las más de 5000 publicaciones descritas durante más de 30 años de investigación, las que han facilitado la comprensión del mecanismo de transporte de esta proteína integral de membrana (11).

\section{ESTRUCTURA}

En un inicio, la bR fue conocida como el constituyente mayoritario del lisado de la membrana celular de Halobacterium salinarum, a esta fracción de color púrpura se le denominó membrana púrpura (MP); estudios posteriores utilizando microscopía electrónica evidenciaron un arreglo organizado, casi geométrico, que le confería peculiares características $(12,13)$.

Estudios por medio de Cristalografía Electrónica de Alta Resolución y Difracción de Rayos X mostraron la formación de entramados hexagonales bidimensionales cristalinos que abarcaban casi toda la superficie de la membrana celular, estos datos facilitaron posteriores análisis de su estructura (14). Un mapa de la densidad electrónica dispersa a baja resolución (LR-MESD, Low Resolution 
Map Electrón Scattered Density) de la MP reveló agrupaciones de siete picos perpendiculares a la superficie de la membrana (15), que correspondían a siete hélices transmembrana, esta estructura permitió deducir la naturaleza proteica del principal componente de la MP. Esta proteína presenta en su interior una molécula de retinal responsable de su función como bomba de protones, similar a la rodopsina de los mamíferos (16). Por estas características se le denominó bacteriorrodopsina, en referencia a su origen bacteriano (hasta entonces no se hablaba del dominio Archaea).

La bR pudo ser separada de los constituyentes lipídicos de la membrana mediante técnicas de permeabilidad en gel y HPLC en fase reversa. La secuenciación de la proteína se basó en la combinación de métodos automatizados de Degradación de Edman y Espectrometría de Masas (17). La secuencia aminoacídica permitió conocer mejor la estructura de la bR y elaborar modelos tridimensionales sofisticados.

La bR es una proteína de $26 \mathrm{kDa}$, formada por 248 aminoácidos que forman una cadena polipeptídica con siete $\alpha$-hélices transmembrana denominadas: A, B, C, D, E, F y G (Fig. 1). La fracción proteica se conoce como bacterio-opsina (bO), cuando ésta se enlaza a una molécula de retinal recibe el nombre de bacterio-rodopsina (bR). Los estudios de comparación de la secuencia de aminoácidos de la $b R$ con sus homólogos funcionales, análisis de mutantes y estudios de digestión proteolítica demostraron que los aminoácidos que interconectan las hélices son cortos y que los extremos amino (N) y carboxilo (C) están dirigidos hacia el espacio extracelular e intracelular respectivamente $(19,20$, $21,22)$. A diferencia de otras proteínas transmembrana la bR se inserta totalmente en la porción hidrófoba de la membrana tanto así que sus lazos sobresalen escasamente hacia la superficie (23). Las siete $\alpha$-hélices forman un poro por el cual se desplaza el protón en cuyo centro una molécula de retinal aldimina se enlaza al grupo $\varepsilon$-amino de Lys-216 de la hélice $G$ formando una base de Schiff $(24,25)$, es aquí donde se realiza el fenómeno fotoquímico.

La región extracelular posee residuos cargados como Asp-212, Arg-82, Glu-204, Glu-194 y polares como Tyr-57, Tyr-185, todos ellos cumplen roles específicos siendo Asp-85, el primer aceptor del protón expulsado (26). La superficie intracelular en cambio tiene residuos hidrofóbicos a excepción de Asp-96 que toma un protón del citoplasma para luego cederlo al retinal desprotonado.

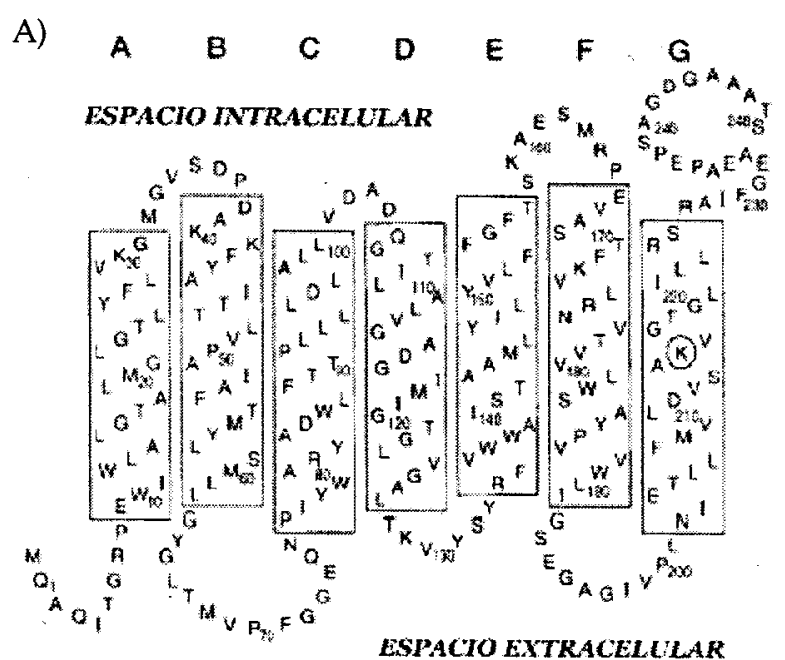

B)

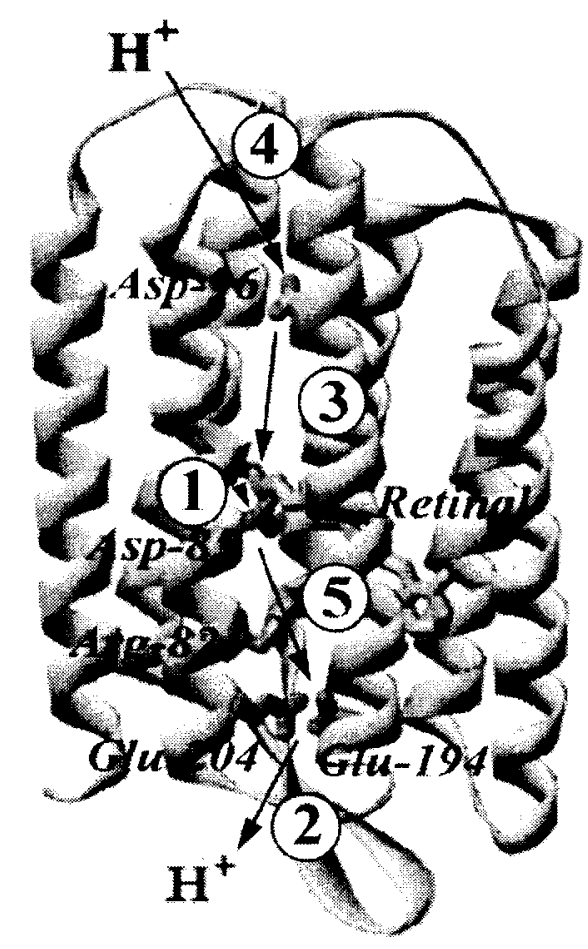

Figura 1. Esquema estructural de la bacteriorrodopsina. A, Estructura secundaria (18); B, Modelo en cintas (33). Las letras indican los 248 aminoácidos que forman las siete áhélice y en un círculo se presenta a Lys-216 donde enlaza el retinal. Las flechas y números en la Fig. B indican la trayectoria del protón desde el espacio extracelular al intracelular y el orden del fotociclo respectivamente.

La MP esta constituida por un conjunto de bR y lípidos, la bR se agrupa en trímeros conformando un entramado hexagonal; por cada molécula de $b R$ hay de seis a siete fosfolípidos, de dos a tres sulfoglicolípidos y un escualeno; los sulfoglicolípidos y el escualeno son lípidos sulfonados y se encuentra exclusivamente en la MP de las haloarqueas. Estos lípidos rodean y se inter- 
ponen en las cavidades de cada trímero de bR formando un complejo lipoproteíco que estabiliza y favorece el perfecto ensamblado y conformación hexagonal de los trímeros en toda la membrana; las interacciones hélice-hélice, lazo-hélices, lazolazo, intertrímeros e interacciones específicas con los lípidos determinan la estabilidad. El ensamblado de la bR desde el citoplasma a la MP se realiza de preferencia perimétricamente, en la fase temprana de inducción las agrupaciones de MP pueden alcanzar diámetros de $0,5 \mu \mathrm{m}$ conteniendo 6 000 trímeros o 18000 monómeros, en fases tardías los parches de MP se fusionan y ocupan hasta el $50 \%$ de la superficie celular $(27,28)$.

\section{FOTOCICLO Y MECANISMO DE CATÁLISIS VECTORIAL}

La unión de una molécula de retinal al residuo Lys216 de bR $(24,25)$ permite que la bR funcione como bomba de protones. Desde que se postuló que la bR funciona como un fotorreceptor (29), numerosos estudios fueron dirigidos a elucidar los mecanismos por los cuales un simple fotón de luz excita a la $b R$ y le hace expulsar un protón para generar un gradiente que luego es aprovechado en la síntesis de ATP por medio de una ATPasa. Las mediciones en tiempo real, de los cambios de absorción del cromóforo retinal de la $b R$ después de ser excitado por un pulso láser la señalaban como responsable de la fotorrecepción; asimismo, la bR presentaba cambios de conformación consecutivos y específicos para cada longitud de onda del espectro visible (30).

Cuando el C15 del retinal se une al grupo $\varepsilon$-amino de Lys 216 forman una base de Schiff, este tiene absorciones características, el cambio conformacional de (13-cis) $\rightarrow$ (13-trans) $\rightarrow$ (13-cis) por acción de un fotón de luz le hace expulsar un protón, a estos cambios se les denomina fotociclo y han sido descritos en diferentes publicaciones $(26$, $31,32,33,34)$. El modelo original del fotociclo descrito por Lozier y col. (35) es el más aceptado y es el siguiente:

$$
\mathrm{BR} \rightarrow \mathrm{K} \rightarrow \mathrm{L} \rightarrow \mathrm{M} \rightarrow \mathrm{N} \rightarrow \mathrm{O} \rightarrow \mathrm{BR}
$$

Cada letra representa un estado conformacional diferente con su absorción característica. El núcleo proteico donde se aloja el retinal es un «bolsillo perfecto", ya que los residuos aromáticos (36) y los lípidos que constituyen la MP $(37,38)$, así como las moléculas de agua específicas que funcionan como grupos polares móviles y el transporte de los protones de un residuo a otro (39) estabilizan los estados intermediarios y son claves para el fotociclo.
A)

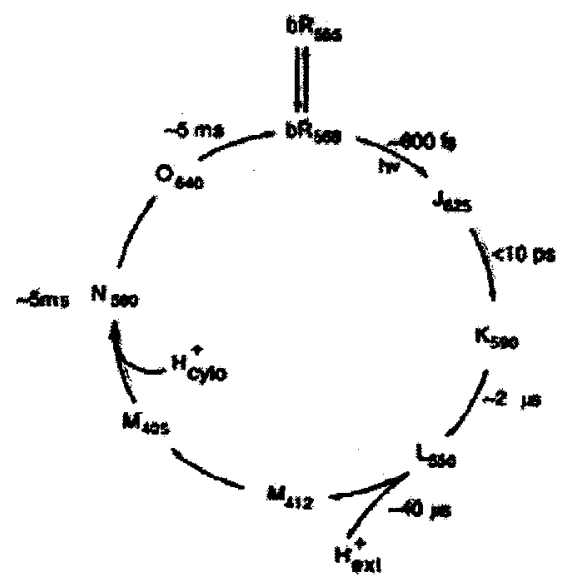

B)
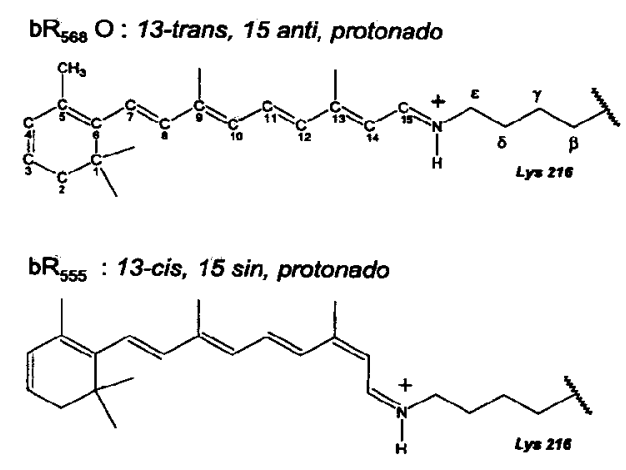

L, N : 13-cis, 15 anti, protonado

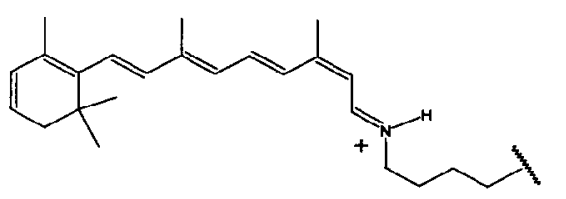

M : 13-cis, 15 anti, desprotonado Lys 216

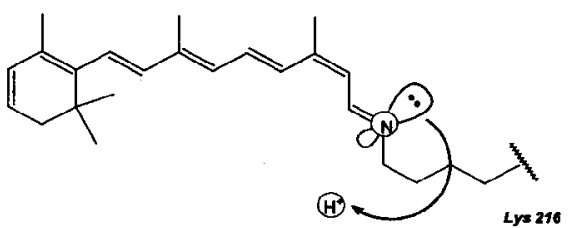

Figura 2. Esquema del fotociclo de la bacteriorrodopsina. A, Se indican los estados de absorción de $h v$ en $\mathrm{nm}$ como subíndices asi como el lapso entre ciclos. B, Cambios conformacionales del retinal en cada intermedio del fotociclo (31).

La molécula de retinal es considerada un pigmento, posee enlaces $\pi$ conjugados, por esto se explica la coloración púrpura de las $b R$, ya que en su estado relajado antes de iniciar el fotociclo absorbe $h v$ a $568 \mathrm{~nm}$ (31), esto corresponde al verde, y refleja los demás colores que en conjunto hacen percibir el color púrpura (40). Las bases de Schiff usualmente absorben $h v$ a $460 \mathrm{~nm}$ (azul) por lo que reflejan el color amarillo-naranja, pero las bR absorben ho a $568 \mathrm{~nm}$, este fenómeno es conocido como 
"opsin shift» y se explica por el desplazamiento batocrómico que ejerce las interacciones de proteína ligada haciéndole absorber a mayor longitud de onda (41).

De forma abreviada el fotociclo comprende (Fig. 2):

- Reacción primaria. La fotoisomerización del retinal todo trans a 13-cis. BR J600 $\rightarrow$ K590 es un proceso estereoselectivo. Un fotón de 568 $\mathrm{nm}$ (luz verde) impacta en el retinal en aproximadamente $600 \mathrm{fseg}$, el retinal todo trans se isomeriza a 13-cis pasa a un intermediario $\mathrm{J} 600$ para luego llegar a K590, todo esto ocurre en menos de 10 pseg.

- Intermedio $\mathrm{K} 590 \rightarrow$ L550 se realiza en aproximadamente $2 \mu \mathrm{seg}$, hay una interacción entre Asp-85 extracelular y el retinal mediada por puentes de hidrogeno, también participan moléculas de agua que refuerzan esa interacción.

- Primera translocación del protón. Intermedio L550 $\rightarrow$ M412, el retinal cede su protón a Asp85 extracelular, el cual lo expulsa al final del ciclo, sucede en aproximadamente $40 \mu \mathrm{seg}$.

- Cambio M412-Extracelular $\rightarrow$ M412Intracelular, simplemente es un cambio de dirección del ciclo, la $\mathrm{b} R$ presenta coloración amarilla.

- Segunda translocación de protón. M412 $\rightarrow$ N560, el Asp-96 intracelular cede su protón al retinal reprotonándolo y lo recupera en este mismo intermedio, tiene una duración de aproximadamente $5 \mathrm{mseg}$.

- Termoisomerización del retinal 13-cis a todo trans. N560 $\rightarrow$ O640, los Asp-85 y Asp-96 están protonados.

- $\mathrm{O} 640 \rightarrow$ BR. La desprotonación de Asp-85 completa el ciclo y la bR vuelve a su estado inicial. Esto sucede en aproximadamente $5 \mathrm{mseg}$.

Es así que la bR expulsa un protón, denominándose a este proceso catálisis vectorial (Fig. 3). Si bien es cierto que los intermedios del fotociclo están definidos, el trayecto individual del protón aún es tema de investigación.

En el año 2002, la Unión Internacional de Bioquímica y Biología Molecular (UIBBM), en un sistema análogo a la nomenclatura de las enzimas,

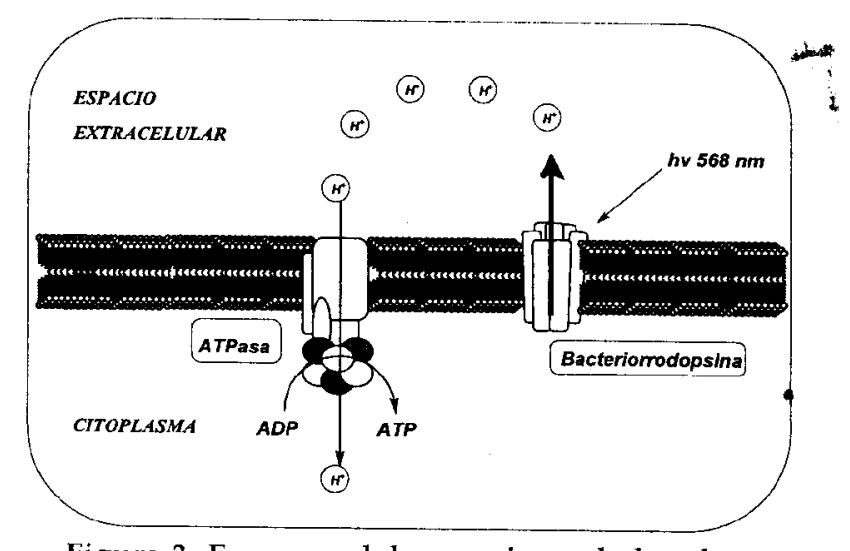

Figura 3. Esquema del mecanismo de bombeo de protones por la bR y síntesis de ATP. Luz $\operatorname{con} \lambda=568 \mathrm{~nm}$ incide en la bR e inicia la expulsión de protones al medio extracelular, éstos regresan al citoplasma por medio de una ATPasa.

clasifica a todas las proteinas de transporte, siendo la bR considerada como 3.E.1 (transporte activo primario - bombas dependientes de luz bacteriorrodopsina)

\section{EXPRESIÓN GÉNICA DE LA BACTERIORRODOPSINA}

Una vez identificada la bR en Halobacterium salinarum como la única proteína constitutiva de la MP no se hicieron esperar los estudios que develaran los procesos de expresión y regulación génica en otras arqueas halófilas extremas, así como las señales ambientales que inducen la expresión de la bacteriorrodopsina, esta molécula motivó a los científicos a plantearse una serie de preguntas como: ¿La deficiencia de nutrientes $\mathrm{u} \mathrm{O}_{2}$ inducen la expresión génica?, ¿Qué otras halófilas extremas poseen el gen?, ¿La bR se relaciona filogenéticamente con otras macromoléculas?, ¿Es su secuencia aminoacídica o función conservada?, ¿Es patrimonio absoluto de las haloarqueas?.

En 1981, se purificó parcialmente el ARNm de la bR de Halobacterium salinartum, luego se sintetizó ADN complementario con la transcriptasa inversa y se secuenció el extremo $5^{\circ}$. Se obtuvo una secuencia de 80 nucleótidos que permitió deducir que la $\mathrm{b} R$ contiene un péptido señal de 13 aminoácidos $(42,43)$.

En 1984, se descubrió que el gen bop es alterado por secuencias de inserción (IS), que normalmente afectan los genomas de bacterias y eucariotas (44, 45). Posteriormente se identificó un gen constitutivo denominado brp (bacterio-opsin related protein) 
que afecta la expresión del gen bop, este nuevo gen presenta mucha similitud con el gen bop, codifica una proteína de 359 aminoácidos, además la predicción de su estructura secundaria indica la presencia de seis hélices hidrofóbicas que fácilmente podrían anclarse en la membrana, su función en ese entonces no estaba muy clara y se pensaba que podría tener función reguladora (46).

En 1988, se identificó un segundo gen involucrado en la expresión de bacterio-opsina $(\mathrm{bO})$ se le denominó bat (bacterio-opsin-activator-gene) (47), al analizar las secuencias de mutantes Bop- que presentaban alteraciones en las posiciones -2 000 a $-3000 \mathrm{pb}$ del gen bop, se localizó un marco de lectura abierta de 2022 pb muy cerca del gen brp y que se transcribe en dirección opuesta al gen bop. El gen bat codifica una proteína de 647 aminoácidos de naturaleza hidrosoluble y con aminoácidos ácidos. Estudios de delecciones e inserciones en secuencias de brp, bat y bop indican que bat esta involucrado en la expresión de brp y bop cuya función sería estabilizar la transcripción de estos genes. Anteriormente, a brp se le atribuía una función reguladora o mediadora en el ensamblado de bR en la MP, pero el descubrimiento de la participación de bat en la regulación anularon esa hipótesis. El grupo de genes bop, brp y bat presentan una transcripción compleja y por ende, su regulación también lo es (Fig. 4) (48), del mismo modo, la síntesis de MP requiere de una coordinación precisa entre la expresión del gen bop y la biosintesis de retinal $(50,51)$ participando la luz y el oxígeno como factores ambientales (29).

En 1999, Baliga y DasSarma., realizaron estudios sobre la superhelicidad de las regiones promotoras, atribuyéndole una cualidad sine qua non para la expresión del gen bop. Estudios posteriores de mutagenesis de las secuencias pribnow (caja TATA) y UAS (upstream activator sequence) demos-

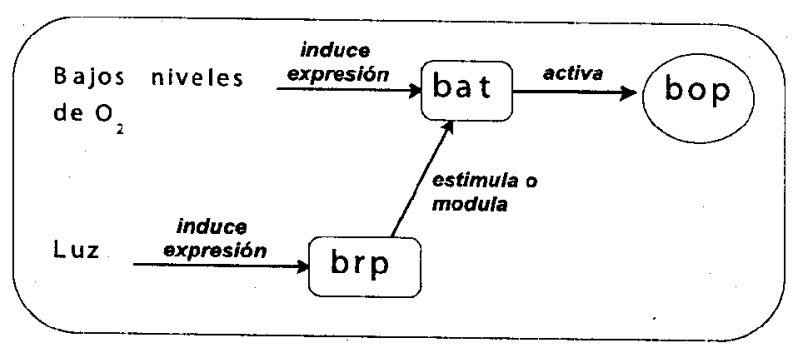

Figura 4. Primer esquema de regulación del gen bop postulado por Shand y Betlach (49). traron que la modificación de esta secuencia altera la expresión del gen bop (52). Cabe señalar que la bR se expresa cuando el medio es altamente hipóxico más no estrictamente anaeróbico, ya que la biosíntesis de retinal requiere trazas de oxígeno (7). Los genes bop y gvp A (gas vesicles protein) de $H$. salinarum (53) que se expresan en medios con baja tensión de oxígeno y alta radiación, son un buen modelo para la realización de estudios de regulación de la expresión génica. Similares casos se presentan en Klebsiella pneumoniae y Rhodopseudomonas capsulata cuyos genes sensores de $\mathrm{O}_{2}$ denominados nifL (nitrogen fixing), son inhibidos por altas concentraciones de $\mathrm{O}_{2} \mathrm{e}$ inhibidores de la ADN girasa (54), enzima necesaria para el superenrollamiento de las regiones promotoras. Además se demostró que la novobiocina, un inhibidor de la ADN girasa, disminuye los niveles de ARNm del gen bop y por ende de gopA, en consecuencia el efecto inhibitorio de la novobiocina se ejerce sobre las zonas promotoras de los genes bat y brp. Al comparar las secuencias de bat, brp y bop con nifL se observó una gran similitud entre bat y nifL, postulándose que el gen bat podría ser un sensor de oxígeno (55).

Las bacteriorruberinas son un grupo de cuatro a seis isoprenoides hidroxilados de 50 carbonos que le confieren el color rojo-anaranjado característico de Halobacterium sp. Las bacteriorruberinas están relacionadas con la biosíntesis del retinal (caroteno = dos moléculas de retinal) además, se propuso una regulación en conjunto con los genes que participan en la síntesis de bR, para demostrar esta hipótesis se utilizaron cepas nativas y mutantes de esta especie y se encontró que la exposición a luz intensa induce altas concentraciones de ARNm de brp y mitiga el efecto inhibidor del $\mathrm{O}_{2} ; \mathrm{y}$ una baja tensión de $\mathrm{O}_{2}$ estimula la síntesis de ARNm de bat. Todos estos datos sugieren que bat codifica una proteina que puede ser un activador o un intermediario en la expresión del gen bop a bajos niveles de $\mathrm{O}_{2}$ (56). Un nuevo gen fue identificado cerca de bat, se le denominó gen blp (bacterio-opsin linked product) éste es pequeño en comparación a los otros, se transcribe en la misma dirección que bop y no se le atribuyó función alguna (57). Los genes involucrados en la síntesis de las proteínas de las vacuolas de gas, retinal, y bacteriorruberinas son regulados por una baja tensión de $\mathrm{O}_{2}$ y altas intensidades de luz. Estos genes y el gen bop pueden formar una familia multigénica denominada modulón o estimulón, los cuales son activados por parámetros ambientales comunes (58). 


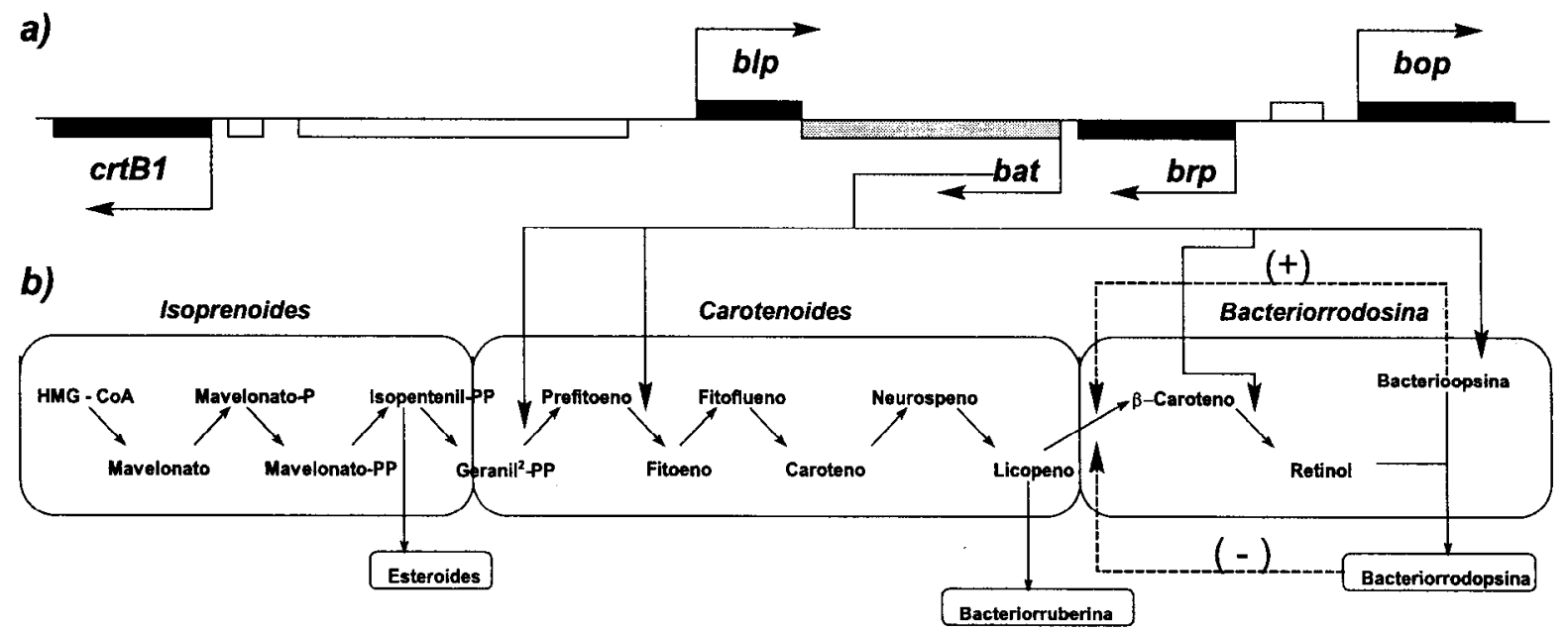

Figura 5. Regulón bR. A, Organización de los genes que participan en la síntesis de bR, las flechas indican la dirección de la transcripción, los genes en negro son regulados por bat. B, Los tres biomódulos de la síntesis de carotenoides, bat regula transcripcionalmente los pasos enzimáticos señalados con flechas, las líneas punteadas indican control positivo o negativo de la enzima que cataliza el paso de licopeno a $\beta$-caroteno (61).

La secuenciación del genoma de Halobacterium sp. (59) permitió entender muchas funciones metabólicas, determinar la presencia de transportadores, sistemas de replicación, transcripción y transducción e identificar genes que codifican enzimas únicas a partir de la comparación de secuencias homólogas con otros organismos. Los análisis de secuencias llevaron por un lado a confusiones, por ejemplo se encontraron genes que codifican enzimas de rutas metabólicas inexistentes; y por el otro, permitió descubrir el gen blh en Halobacterium sp. NRC-1 un parólogo del gen $b r p$, y entender mejor su participación en la síntesis de retinal.

Por técnicas de knockout se demostró que el gen blh es esencial para la síntesis de bR pero no de bO, además al no haber retinal se incrementa el $\beta$-caroteno. Los genes brp y blh no participan en la regulación del gen bop ya que su delección solo afecta la síntesis de retinal, si se añade retinal de una fuente exógena se restaura los niveles de $b R$. Todos estos datos sugerían que los genes brp y blh codifican proteínas que forman parte de una nueva ruta biosintética de retinal, única en haloarqueas. Se postula que pueden ser enzimas claves en la síntesis y unión del retinal a bO, e incluso enzimas multifuncionales (60). Además, se encontró que el gen crtB1 relacionado con la síntesis de caroteno, también es regulado transcripcionalmente por el gen bat.

Las herramientas bioinformáticas ayudaron a esclarecer la interrelación del grupo de genes que participan en la síntesis y regulación de bR ahora denominados regulón bR (Fig. 5) (61). El análisis de las secuencias UAS homólogas al gen bop y factores de transcripción en los tres dominios establecidos por Woese presentaron similitudes con las secuencias de aminoácidos de proteínas de origen vegetal, atribuyéndole un origen ancestral común, además se han encontrado homólogos de la bR en hongos y en una $\gamma$-proteobacteria (62). Para definir la función de los genes del regulón bR se hizo un análisis de las UAS de Halobacterium sp. y se encontró que el gen crtB1 es un homólogo de fitoeno sintetasa clave en la sintesis de carotenoides, el gen brp cataliza el paso final del clivaje oxidativo de $\beta$-carotenos y que el gen blp presenta similitud a una proteína asociada a la biosíntesis de bacterioclorofilas / porfirinas y carotenoides. Usando el algoritmo PFAM se identificó en las secuencias del gen bat dominios aminoacídicos GAF relacionados con sensores de luz, PAC/PAS sensores redox y ligandos HTM DNA. Los dominios GAF se encuentran en bacterias y eucariotas, son conservados en fitocromos y fosfodiesterasas GMPc específicos. Al estar GAF y PAC/PAS asociados con ligandos HTM DNA, clasifican a Bat como proteína transductora citoplasmática sensible a cambios de luz y potencial redox. Secuencias UAS parecidas a los del gen bop muestran gran similitud con el gen pds de tomate el cual esta asociado a genes que participan en la síntesis de carotenoides frente al estrés oxidativo (63). El cstudio global de la regulación de los sistemas transductores de energía en haloarqueas por medio de herramientas bioinformáticas permite deducir la regulación e 
interrelación de varias rutas bioquímicas relacionadas con el fototrofismo, la síntesis de isoprenoides, carotenoides y ensamblaje de bR (61).

\section{POTENCIAL BIOTECNOLÓGICO}

La excelente estabilidad termodinámica y fotoeléctrica de la bR la han hecho susceptible de aplicaciones tecnológicas que aprovechan sus propiedades fotoeléctricas, fotoquímicas y protoncinéticas (64) entre las que se destacan:

- La propiedad fotocrómica y de conversión de luz en energía puede explotarse para el diseño de moduladores de luz y en monitores de alta resolución. A diferencia de los monitores convencionales de 4 líneas $/ \mathrm{mm}$, los monitores con $\mathrm{bR}$ ofrecen 100 líneas $/ \mathrm{mm}$ necesarios por ejemplo en telecirugía (65).

- En microelectrónica se está estudiando a la bacteriorrodopsina como elemento matriz funcional en una nueva tecnología microestructural no tóxica para sustancias a base de silicio o para circuitos integrados. Con estos avances se está llegando a la biocomputación y a la era de los computadores orgánicos ¿Podrá el biochip reemplazar a los chips de silicio?

- La elaboración de discos de almacenamiento de datos de alta capacidad que permite almacenar más de 10000 gigabytes, además éstos son flexibles, reciclables y no tóxicos.

- La construcción de celdas fotovoltaicas. Al ser iluminada la bR, ésta transporta carga eléctrica en una dirección y produce energía electrostática. Este mecanismo tiene distintas aplicaciones técnicas y potenciales en el campo de la tecnología fotovoltaica, se espera que en unos 10 años se puedan construir celdas fotovoltaicas basadas en el centro activo de la reacción fotosintética, aunque los prototipos iniciales se prevén mucho antes.

- Sistemas convertidores de energía luminosa en química. En presencia del detergente octiltioglucosido las bR forman espontáneamente vesículas de 17,9 a 19,0 nm de diámetro, las cuales pueden ser utilizadas como convertidores de energía luminosa en química, considerando que la producción de ATP es de gran utilidad en procesos biotecnológicos que demanden alta energía.

- Generación de señales eléctricas en los convertidores fotoeléctricos de imágenes, sensores de movimiento y retinas artificiales.

\section{CONCLUSIONES Y PERSPECTIVAS}

En esta revisión se presenta los avances científicos de la bacteriorrodopsina, molécula muy peculiar, que ha facilitado el diseño de diferentes técnicas para el estudio de numerosas proteínas así como la elucidación de su estructura, regulación, mecanismos de acción y su aplicación biotecnológica potencial en la elaboración de biochips, retinas artificiales, fotoceldas, etc.

La versatilidad de las propiedades físicas y químicas de la bR favorecen sus múltiples aplicaciones en el campo de la biocomputación y bioelectrónica, siendo de gran interés comercial la obtención de $b R$ de fuentes naturales para ofertarlo como materia prima a gran escala. El aislamiento y caracterización de microorganismos halófilos extremos productores de bR de salares y salinas solares del Perú permitirán contar con recursos nativos con un incalculable valor industrial.

\section{REFERENCIAS BIBLIOGRÁFICAS}

1. Woese CR, Fox GE. Phylogenetic structure of the prokaryotic domain: the primary kingdoms. Proc Natl Acad Sci USA 1977; 74:5088-5090.

2. Woese CR. Bacterial evolution. Microbiol Rev $1977 ; 51: 221-271$

3. Dyall-Smith M. The halohandbook. Protocols for halobacterial genetics. Haloarcheal Genetics Laboratory. 2003; University of Melbourne. Australia.

4. DasSarma S, Arora P. Halophiles. Encyclopedia of life sciences 2001. Nature Publishing 2001; Group. 1-9

5. Gonzáles JC, Peña A. Estrategias de adaptación de microorganismos halófilos y Debaryomyces hanseni (levadura halófila). Rev Lat Microb 2002; 44:137-156

6. Kennedy S, Ng W, Salzberg S, Hood L, DasSarma S. Understanding the adaptation of Halobacterium species NRC-1 to its extreme environment trough computational analysis of its genome sequence. Genome Research 2001; 11:1641-1650

7. Hartmann R, Sickinger $H$, Oesterhelt D. Anaerobic growth of halobacteria. Proc Natl Acad Sci USA 1980; 77:3821-3825

8. Schafer G, Engelhard M, Muller V. Bioenergetics of the Archaea. Microbiol Mol Biol Rev 1999; 63:570-620 
9. Skulachev VP. Bioenergetics of extreme halophiles. In M. Kates D, Kushner J, Matheson A.T.(ed.) The biochemistry of archaea. Elseiver, Amsterdam. The Netherlands 1993; p.25-39

10. Danon A, Stockenius W. NASA Symp. Extreme Enviroments. Mechanism of microbial adaptation, Ames Res Ctr Moffett Field, Calif., June 1972; p. 25

11. Lanyi JK. Bacteriorhodopsin. Biochimica et Biophysica Acta 2000; 1466:1-3

12. Stoeckenius W, Rowen R. A morphological study of Halobacterium halobium and its lysis in media of low salt concentration. J Cell Biol 1967; 34:365-393

13. Stoeckenius W, Kunau W. Further characterization of particulate fraction from lysed cell envelopes of Halobacterium halobium and isolation of gas vacuole membranes. J Cell Biol 1968; 38:337-357

14. Blaurock AE, Stoeckenius W. Structure of the purple membrane. Nat New Biol 1971; 233:152-155

15. Henderson R, Unwin PN. Three-dimensional model of purple membrane obtained by electron microscopy. Nature $1975 ; 257: 28-32$

16. Krzysztof B. Visual and archaeal rhodopsins: similarities, differences and controversy. Cell Mol Biol Lett 2003; 8:285-296

17. Khorana HG, Gerber GE, Herlihy WC, Gray $\mathrm{CP}$, Anderegg RJ, Nihei K, Biemann K. Amino acid sequence of bacteriorhodopsin. Proc Natl Acad Sci USA 1979; 76:5046-5050

18. Thomas M. Refolding of bacteriorhodopsin from expressed polypeptide fragments. J Biol Chem 1998; 273:9312-9322

19. Henderson R, Baldwin JM, Ceska TA, Zemlin F, Beckmann E, Downing KH. Model for the structure of bacteriorhodopsin based on highresolution electron cryo-microscopy. J Mol Biol $1990 ; 213: 899-929$

20. Grigorieff N, Ceska TA, Downing KH, Baldwin JM, Henderson R. Electron-crystallographic refinement of the structure of bacteriorhodopsin. J Mol Biol 1996; 259:393421
21. Kimura Y, Vassylyev DG, Miyazawa A, Kidera A, Matsushima M, Mitsuoka K, Murata K, Hirai T, Fujiyoshi Y. Surface of bacteriorhodopsin revealed by high-resolution electron crystallography. Nature 1997; 389:206-211

22. Luecke H, Schobert B, Richter HT, Cartailler JP, Lanyi JK. Structure of bacteriorhodopsin at 1.55 Å resolution. J Cell Biol 1999; 291:899-911

23. Heymann J, Muller D, Landau E, Rosenbush J, Pevay-Peyroula E, Buldt G, Engel A. Charting the surfaces of the purple membrane. J Struc Biol 1999; 128:243-249

24. Bayley H; Huang KS, Radhakrishnan R, Ross AH, Takagaki $Y$ and Khorana HG. Site of attachment of retinal in bacteriorhodopsin. Proc Natl Acad Sci USA 1981; 78:2225-2229

25. Lemke HD, Oesterhelt D. Lysine 216 is a binding site of the retinyl moiety in bacteriorhodopsin. FEBS Lett. 1981; 128:255260

26. Luecke H, Richter HT, Lanyi JK. Proton transfer pathways in bacteriorhodopsin at $2.3 \AA$ resolution. Science 1998; 280:1934-1937

27. Krebs M, Isenbarger T. Structural determinants of purple assembly. Biochimica et Biophysica Acta 2000; 1460:15-26

28. Oesterhelt F, Oesterhelt D, Pfeiffer M, Engel A, Gaub HE, Müller DJ. Purple membranes of $H$. salinarum typical high-resolution AFM topograph of the cytoplasmic surface of a wild-type purple membrana. Science 2000; 288:143-146

29. Oesterhelt D, Stoeckenius W. Functions of a new photoreceptor membrane. Proc Natl Acad Sci USA 1973; 70:2853-2857

30. Kumar HK, Gowda A. Absorption characteristics of bacteriorhodopsin molecules. PRAMANA-J Phys 2000; 54:447452

31. Hatcher $M, H u J G$, Belenky $M$, Verdegem $P$, Lugtenburg J, Griffin RG, Herzfeld J. Control of the pump cycle in bacteriorhodopsin: mechanisms elucidated by solid-state NMR of the D85N mutant. Biophys J 2002; 82: 10171029 
32. Edman K, Nollert P, Royant A, Belrhali H, Pebay-Peyroula E, Hajdu J, Neutze R, Landau E. High-resolution X-ray structure of an early intermediate in the bacteriorhodopsin photocycle. Nature 1999; 401:822-826

33. Luecke H, Schobert B, Richter HT, Cartailler JP, Lanyi JK. Structural changues in bacterirhodopsin during ion transport at $2 \AA$ resolution. Science 1999; 286:255-260

34. Brown LS. Proton transport mechanism of bacteriorhodopsin as revealed by site-specific and protein sequence variability. Biochemistry (Moscow) 2001; 66:1249-1255

35. Lozier RH, Bogomolni RA, Stoeckenius W. Bacteriorhodopsin: a light-driven proton pump in Halobacterium halobium. Biophys $\mathbf{J}$ $1975 ; 15: 955-962$

36. Tajkhorshid E, SuhaiS. The effect of the protein environment on the structure and charge distribution of the retinal schiff base in bacteriorhodopsin. Theor Chem Acc 1999; 101:180-185

37. Hendler RW, Dracheva S. Importance of lipids for bacteriorhodopsin structure, photocycle and function. Biochemistry (Moscow) 2001; 66:1311-1314

38. Szundi I, Stoeckenius W. Effect of lipid surface charges on the purple-to-blue transition of bacteriorhodopsin. Proc Natl Acad Sci USA 1987; 84: 3681-368

39. Maeda A. Internal water molecules as mobile polar groups for light-induced proton translocation in bacteriorhodopsin and rhodopsin as studied by difference FTIR spectroscopy. Biochemistry (Moscow) 2001; 66: $1256-1268$

40. Bender GT. Métodos instrumentales de análisis en química clínica. Ed. Acribia-Zaragoza 1992; p.37

41. Hu J, Griffin RG, Herzfeld J. Synergy in the spectral tuning of retinal pigments: complete accounting of the opsin shift in bacteriorhodopsin. Proc Natl Acad Sci USA 1994; 91:8880-8884

42. Chang H, Majumdar A, Dunn R, Makabe $O$, RajBhandary UL, Khorana HG, Ohtsuka E, Tanaka T, Taniyama YO, Ikehara $M$. Bacteriorhodopsin: partial sequence of mRNA provides amino acid sequence in the precursor region. Proc Natl Acad Sci USA 1981; 78:3398-3402

43. Dunn R, McCoy J, Simsek M, Majumdar A, Chang H, RajBhandary UL, Khorana HG. The bacteriorhodopsin gene. Proc Natl Acad Sci USA $1981 ; 78: 6744-6748$

44. Pfeifer F, Friedman J, Boyer HW, Betlach M. Characterization of insertion affecting the expresion of the bacterio-opsin gen in Halobacterium halobium. Nucleic Acids Res $1984 ; 12: 2489-2497$

45. Simsek M, DasSarma S, RajBhandary UL, Khorana HG. A transposable element from Halobacterium halobium which inactivates the bacteriorhodopsin gene. Proc Natl Acad Sci USA 1982; 79:7268-7272

46. Betlach M, Friedman J, Boyer HW, Pfeifer F. Characterization of halobacterial gene affecting bacterio-opsin gene expresión. Nucleic Acids Res 1984; 12:7949-7959

47. Leong D, Pfeifer F, Boyer HW, Betlach M. Characterization of a second gene involved in bacterio-opsin gene expression in a halophilic archaeabacterium. J Bacteriol 1988; 170:49034909

48. Leong D, Boyer HW, Betlach M. Transcription of gene involved in bacterio-opsin gene expresion in mutants of a halophilic archaeabacterium. J Bacteriol 1988; 170:49104915

49. Shand R, Betlach M. Expression of the genecluster of Halobacterium halobium is induced by low oxigen tension and by light. J Bacteriol 1991; 173:4692-4699

50. Sumper M, Herrmann G. Biogenesis of purple membrane: regulation of bacterio-opsin synthesis. FEBS Lett 1976; 69:149-152

51. Sumper M, Herrmann G. Biosynthesis of purple membrane: control of retinal synthesis by bacterio-opsin. FEBS Lett 1976; 71:333-336

52. Baliga N, DasSarma S. Saturation mutagenesis of the TATA box and upstream activator sequence in the haloarchaeal bop gene promoter. J Bacteriol 1999; 181:2513-2518

53. Krantz MJ, Ballou CE. Analysis of Halobacterium halobium gas vesicles. J Bacteriol 1973; 114:1058-1067 
54. Dixon $M$, Henderson NC, Austin S. DNA supercoiling and aerobic regulation of transcription from the Klebsiella pneumoniae nifL promoter. Nucleic Acids Res 1988; 16:9933-9946

55. Chin-Fen Y, DasSarma S. Transcriptional induction of purple membrane and vesicle synthesis in the archaeabacterium Halobacterium halobium is blocked by a DNA gyrase inhibitor. J Bacteriol 1990; 172:4118-121

56. Gropp F, Betlach M. The bat gene of Halobacterium halobium encodes a transacting oxygen inducibility factor. Proc Natl Acad Sci USA 1993; 91:5475-5479

57. Gropp F, Betlach M. A fourth gene in the bop gene cluster is co-regulates with the bop gen. Syst Appl Microbiol 1994; 16:716-724

58. Neidhart F, Ingraham J, Schaech M. Physiology of the bacterial cell. Ed. Sinauer Associates, Inc. Sunderland, Mass. 1990; p. 382-383

59. Wailap VN, Kennedy SP, Mahairasa GG, Berquistc B, Pana M, Shuklac HD. Genome sequence of Halobacterium species NRC-1. Proc Natl Acad Sci USA 2000; 97:12176-12181
60. Peck R, Echavarri C, Johonson E, Wailap VN, Kennedy S, Hood L, DasSarma S, Krebs M. brp and $b l h$ are requeride for synthesis of the retinal cofactor of bacteriorhodopsin in Halobacterium salinarum. J Biol Chem 2001; 276:5739-5744

61. Baliga N, Pana M, Goo Y, Eugene C, Goodiett D, Dimitrov K. Coordinate regulation of energy transduction modules in Halobacterium $s p$. analized by a global system approach. Proc Natl Acad Sci USA 2002; 99:14913-14918

62. Beja O, Aravind L, Eugene V, Suzuki M, Hadd A. Bacterial rhodopsin: evidence for a new type of phototrophy in the sea. Science 2000; 289:1902-1906

63. Baliga N, Kennedy S, Ng-Wailap V, Hood L, DasSarma $S$. Genomic and genetics dissection of an archaeal regulon. Proc Natl Acad Sci USA 2000; 98:2521-2525

64. Margesin $R$, Schinner F. Potential of halotolerant and halophilic microorganisms forbiotechnology. Extremophiles 2001; 5: 7383 